\title{
CURRENT ISSUES PERTAINING GENDER- BASED VIOLENCE IN SRI LANKA
}

\author{
Solomons TH \\ Senior Lecturer/ Clinical Psychologist \\ Department of Psychiatry, Faculty of Medicine, General Sir John Kotelawala Defense University \\ (KDU), Sri Lanka
}

\begin{abstract}
A qualitative study was conducted to obtain an understanding of the current attitudes, beliefs, and other related issues related to gender in Sri Lanka. The study used interviews, mini-interviews, and Focused Group Discussions (FGD) for this purpose. The study consisted a few different samples and the majority of the sample was drawn from the health sector. The study explored different cultural regions of Sri Lanka via the FGDs. The objective of the study was to provide insight in to the current situation of gender-based violence (GBV) and related issues in Sri Lanka. The study yielded interesting results which could be explored by future researchers. The salient outcomes were that the strong role of economic factors in GBV was identified, the effect of micro credit facilities and increased substance abuse on GBV were identified. In addition to this insight was gained to the possible issues related to GBV in different cultures in Sri Lanka and GBV in a few industrial settings in Sri Lanka.
\end{abstract}

Keywords: Gender-Based Violence (GBV), Economic factors, Culture, Micro Credit

\section{Introduction}

\section{Purpose of the study}

A qualitative study was carried out to obtain an idea about the nature of attitudes and knowledge gaps regarding gender-based violence in Sri Lanka. The health promotion bureau of the ministry of health had already identified a gap in communication skills among the primary health care field staff members, mainly the public health midwives and public health inspectors. This gap was stated in the Behavior Change Communication manual published by the ministry of health.

As per these observations, it was decided to develop a training manual to provide the required skills for the aforementioned staff members. The author was entrusted with the task of developing the training manual.

Before deciding the content for the manual, a situational analysis was carried out. As the training manual was intended to be developed for health care workers, the research was primarily conducted among health professionals. The current paper has been written on the outcomes and observations made during this situational analysis so that other scholars and researchers could have access to this data. Necessary permissions have been obtained for all organizations involved in the publication of the data. 


\section{Literature review}

There is one universal truth, applicable to all countries, cultures, and communities: violence against women is never acceptable, never excusable, and never tolerable." United Nations Secretary-General, Ban Ki-Moon (2008) (World Health Organization ( WHO), 2013).

United Nations General Assembly defined Violence against women (VAW) in 1993, "as any act of GBV that results in, or is likely to result in, physical, sexual or psychological harm or suffering to women, including threats of such acts, coercion or arbitrary deprivation of liberty, whether occurring in public or in private life" (Glass, 2015) As such the term GBV is often used interchangeably with the term Violence against Women (VAW). Yet there is increased recognition that violence that essentially results from being a member of one gender is also experienced by men and boys.

Violence against women is essentially a fundamental violation of human rights as the United Nations' universal declaration of Human rights in 1945 states that, "human rights apply to all human beings without distinction of gender, although it does not specifically address issues related to women or violence against women" (Glass, 2015)

The most common form of gender-based violence is violence against women. Violence against women can be defined as "any act of verbal or physical force, coercion or life-threatening deprivation, directed at an individual woman or girl that causes physical or psychological harm, humiliation or arbitrary deprivation of liberty and that perpetuates female subordination" (Heise, L, M, \& M, 2002)

Violence against women is categorized as a fundamental violation of human rights and a serious problem of health. Most importantly it is considered the most pervasive violation of human rights. (Heise, L, M, \& M, 2002) While it increases mortality and morbidity, other consequences such as loss of self-esteem can often go unnoticed.

Within GBV two significant areas have been identified. Intimate partner violence (IPV) is perpetrated by an intimate partner and non-partner sexual violence perpetrated by someone other than an intimate partner.

Violence against women has effects spanning many areas of a woman's life. While the consequences can be physical, psychological, and social, health consequences in the areas of physical, sexual, reproductive, and psychological health can be intense. They are at high risk of having a child with low birth weight, more than twice likely to have an abortion, twice as likely to experience depression, and more likely to contract HIV and other STIs.

While $35 \%$ of women worldwide have experienced sexual or physical violence, a larger population experiences other forms of violence. Most of the violence that women experience is perpetrated by intimate partners. 30\% of women worldwide have been in a relationship with a partner who was violent either physically or sexually. Globally $38 \%$ of all women homicides are being committed by intimate partners. 
$7 \%$ of women globally also experience violence from a person other than an intimate partner. Yet research data on this type of violence is scarce. While the health effects of violence perpetrated by persons other than an intimate partner have not been studied adequately, the likely consequences are being predisposed to alcohol use disorders, anxiety disorders, and depressive disorders.

The best argument that points at the preventable nature of gender-based violence is that its prevalence varies across societies. Global variation in prevalence points to the fact that it is not a naturally occurring or an inherent phenomenon that occurs without societal control. This strongly argues for the fact that the change in societal and other factors that give rise to violence can be changed and through that GBV could be prevented. Evidence is accumulating on causes for the global variance in prevalence. Among them, socio-economic factors which foster a culture of violence are strongly implied. Especially change of societal norms that condone male superiority and thereby sanctions violence against women. In addition childhood exposure to violence has also been implied as a cause. Thus making parenting an important variable in gender-based violence. World Health Organization refers to "violence against women as not being a small problem that only occurs in some pockets of society, but rather as a global public health problem of epidemic proportions, requiring urgent action." (World Health Organization ( WHO), 2013)

Some researchers argue that violence is a phenomenon common to both males and females and both males and females are violent to an equal degree in relationships. (Mohd, 2016) Yet GBV is commonly discussed from a female stance, often ignoring the violence directed at men by women.

In a patriarchal society, where men are assigned more power than women, men enjoy the privilege of their powerful position. Yet, while enjoying this powerful position, men also appear to experience pain and isolation due to these gender roles. (Kaufman, 1999) Due to the role of power traditionally assigned to men in patriarchal societies, men have to struggle to ascertain their role as a powerful, dominant member of society in relation to other males. This can lead to a constant power struggle at a personal level and alienation from other male members of society. In addition to that, in the context of heterosexual relationships in a patriarchal society, women may expect a man to ascertain his power among other males as a powerful, dominant member, which may lead to constant attempts to ascertain his powerful position among other males members. These power struggles can develop into lifelong habits and will invariably be carried over to relationships with women. Therefore most male members of a patriarchal social system would be more likely to approach relationships with women as a power relationship, where their power struggle with other male members is also carried on by trying to ascertain their superiority over women. Further, as their constant power struggle is with men usually and rather than women, a woman who challenges the male power would be seen as out of the norms and would be treated as an uncommon situation where the male supremacy has to be quickly ascertained.

While Sri Lanka is believed to be a patriarchal society, Women in Sri Lanka appear to have more favorable conditions compared to other South Asian countries in the region. Yet they have still not achieved gender equality as per International standards. (Asian Development Bank, Deutsche Gesellschaft für Internationale Zusammenarbeit (GIZ) GmbH, 2015) Sri Lanka appears to have a mixed picture with positive indicators in education and health indicators for women, while also having high negative indicators of inequality in domains of employment and political participation and issues of Gender-Based violence. What is interesting is, as a middle-income country, Sri Lanka still has Human 
Development Indicators (HDI) comparable to more developed countries. Yet, compared to these gains in gender inequality is still indicated as high in Sri Lanka. According to the United Nations Development Programme (UNDP) report in 2016, the HDI rank of Sri Lanka is 73, while neighboring India is 131. Yet Sri Lanka ranks 87 in Gender Inequality Index (GII) while compared to their low placement in the HDI, India ranks 125 in GII. (United Nations Development Programme ( UNDP), 2018) This might be an indication of the human development gains of the country being unequally distributed among genders. This is especially important as these inequalities appear while Sri Lanka has a favorable sex ratio of 52\% (World Health Organization Sri Lanka, 2018) for women, where the majority of the population is women.

\section{Research Gap}

At present, there is very little research on GBV and related aspects in Sri Lanka. The above literature that has been discussed stems from mostly descriptive studies, which makes it difficult to make more definitive inferences on the status of GBV in Sri Lanka. One of the main gaps that have been observed was the lack of in-depth, qualitative studies on GBV, upon which more complex studies could be built.

Therefore, the current study has attempted at studying GBV related issues using qualitative techniques to obtain an in-depth understanding of the current situation of GBV in Sri Lanka. It is expected that these qualitative studies would provide a foundation for future researchers to study the more complex aspects of GBV in Sri Lanka.

\section{Participants}

The selected sample was a convenient sample, which comprised of individuals from diverse backgrounds. The majority of the sample were professionals from the health sector.

\section{Mini Interviews}

A convenient sample of four consultants in medicine, two academic sociologists, one filmmaker, two police inspectors participated in the study.

In addition to this, a convenient sample of nursing officers attached to a government hospital in the Colombo district also participated. Nursing officers were from an orthopedic ward, a Sexually transmitted diseases (STD) unit, a Pediatric Ward, and a surgical ward. One of the participants from this category was a male, while all others were females. In addition to that, another convenient sample of young adults, with 3 females and 2 males also participated in mini-interviews. All participants were in their early twenties and were less than 25 years of age.

Another convenient sample of 4 employees from the apparel industry, where 3 were females and one was a male also participated in the study. 


\section{Focus Group Discussions}

60 participants comprising of public health midwives and public health inspectors from 4 different Medical Officer of Health (MOH) areas participated in the focused group discussions (FGD). Namely the four districts were Galle, Hatton, Batticoloa, and Jaffna. The participants were nominated to participate in the FGDs via the health promotion bureau. The Medical officer of health of all these four areas also participated in the discussion.

\section{Procedure}

At all levels of data collection, the participants were provided with a clear debriefing of the purpose of the study. In addition to that, it was made clear that the data collected may be published in diverse forms as per the requirement of the different organizations who were involved in the task of developing the training manual. After the debrief, verbal consent was obtained.

\section{Incentives}

Incentives were provided only for the participants of the FGDs. The standard government allowance for participating in training-related programs and morning tea and lunch was provided for the participants along with stationary.

\section{Analysis}

The qualitative data of all interviews and the FGD's were analyzed using the inductive content analysis, where the common themes that emerged across different samples were coded and summarized as key outcome points. This analysis was done separately for each sub-section of the sample.

\section{Results and Discussion}

\section{Ideas expressed by the professionals}

The key points observed by the consultants in various medical fields were as follows. One of their main concerns was that most patients are not willing to disclose GBV related issues to the health care staff. They pointed out that mainly this was because different team members of the health care team possessed different levels of sensitization in terms of medical ethics in general and ethical concerns in managing GBV related incidents. Most medical consultants felt that in addition to the normal reluctance to disclose something considered as a taboo in society like GBV, part of the reluctance is also due to the aforementioned different levels of knowledge, skills, and attitudes in the health care team. For example, even an attendant in the health care team may have access to some information regarding the patient, though not all. In a situation like GBV, some team members who are not sentient to the ethical principles and other concerns in such a situation may even seek more information from the patient and misuse these. To complicate matters, most patients are unaware of their right to refuse to give information and sometimes do not take the appropriate care in deciding to whom the information must be disclosed and to whom they should not disclose the information.

This was also confirmed when the attitudes, knowledge, skills of different healthcare workers in the current study were compared. Some professionals had highly sophisticated levels of knowledge, skills, 
and attitudes about GBV, keeping with current research developments, while some demonstrated partial knowledge and some were ignorant. Also, it was interesting that most of these professionals had received some level of training on GBV which is a positive fact, though they possessed different explanations of GBV

Most professionals expressed the view that more than they need for male supremacy, the current participation of males and females in day-to-day chores is determined by the economic conditions of the family. For example, professionals working in the oncology field felt that when a woman is diagnosed with cancer, sometimes the woman may have to prematurely assume household responsibilities, not because the man is unwilling to support her, but the economic situation of the family is such, that the male has to earn and there is no money in the family to acquire paid help.

This idea was reiterated by the sociologists and the police officers as well. Most of them pointed out the fact that in families with higher socioeconomic standing, this kind of situation would be managed with paid help. Further, in such families, when there is an excess of the household chores, again paid support can be obtained. Further, as they might have more access to technological innovations to make household chores easier, the burden may also be less.

All professionals also stated that the employment conditions of the lower middle class and lower class economic backgrounds to be structured in such a way that the stress levels are high, while benefits like leave are less and that this may also predispose to an unequal division of labor.

This could be a reflection of the fact that economic stress can lead people to resort to unequal gender participation out of necessity or under stressful circumstances people resort to the well-known traditional bases of gender norms in dividing their day-to-day tasks. It could also be a reflection of the fact that women's economic strength is less compared to men and that women lack economic opportunities, which again is a reflection of the influence of traditionally gendered norms. This conclusion was especially based on the fact that most examples the professionals provided were instances where they portrayed a woman who is burdened by household chores. This could be a reflection of the societal attitude of GBV as primarily a movement to improve the condition for women and therefore, ignoring the fact the males could also be subjected to gender-based violence.

According to the two sociologists, Use of gender stereotypes in the division of labor and other aspects can lead to discrimination and violence against women. In addition to that since there is more power given to the man in the family context via traditional norms and beliefs and gender stereotypes, the division of labor is usually done according to the preferences and to the advantage of the man. Gender stereotypes are accepted most often in absolute terms by both men and women and this is used in dividing labor in a more advantageous way for the man. Yet again, due to the effects of early socialization where children observe the traditional gender-based division of labor, as adults, they may not recognize any issue in perpetuating the same cycle in their own family life. In addition to that, people resist attempts at labeling this traditional division of labor as violence or discrimination. Therefore according to these two experts, sensitizing the public to such issues should be a gradual process and a culture-sensitive process. In addition to that labeling, everything as violence or discrimination would hamper such a process. Therefore culture-sensitive sensitization would mean 
attempting at a gradual change of beliefs and attitudes by educating the possible positive outcomes of the recommended approaches while avoiding too much attention to violence as this has the ability for people to react strongly assuming that their culture is at stake. What should be remembered is in such a situation culture is more powerful to resist healthcare interventions. They are also of the opinion that our culture as any culture will and can change and, that our culture could benefit by creating awareness on gender-related issues. As culture can create such resistance, human Rights-based approaches (HBRA) that are carried out can be a successful alternative for change. In following an HBRA, one can work towards neutralizing the patriarchal concepts associated with women and encourage the society to her as a human being equal to a man and as a human being, entitled to full rights of a human to be free from all forms of violence and discrimination.

When addressing sexual issues in the family contexts, they stated that the same stereotypes prevent a woman from talking about sexual satisfaction. Culturally it is seen more as a male need and the woman is expected to fulfill it. Talking about sexual satisfaction makes males judge women negatively, assuming the woman might have had sexual experiences outside the marriage. Yet according to them, they believed a third party, such as a health care worker talking about the topic of women's satisfaction could be a very effective method in starting sensitizing society to this issue. What they predicted was we cannot expect partners to talk about sex openly after an awareness program or a personal intervention, yet both men and women can be expected to be more attentive to each other's sexual needs and satisfaction.

Increased involvement of women in the drug trade according to the two experts, again is a reflection of the economic issues faced by women. Therefore it cannot be overemphasized that generating more economic opportunities and guidance for women in society would be one of the primary tasks to be done to address gender-related issues.

During the interview with the prominent film director and cinematographer, on the type of genderrelated issues, existent in the film industry, he stated that while employing women for acting is a common thing in the industry, it still does have the traditional cultural stereotypes when it comes to the main positions in film making. Roles such as the film director, camera director, and producer are believed to be traditional male roles. During the entire history of the film industry, only two women have been able to break these barriers and play a prominent role in filmmaking, reportedly via the men they associated with, who were already established in the film industry. Even when women try to get into the industry they are not taken seriously and there are instances where women are coerced into providing sexual favors to get into the industry. In addition to this GBV and sexual bribes are common in recruiting new actresses.

When taken as an industry though there are more women as a whole, the industry itself appears to be dominated by men. This could also mean that women's perspective is not represented in our films. Therefore one thing GBV related policymakers can do would be to take measures to encourage women cinematographers to enter the industry. This is especially important as cinema is a powerful medium in shaping public opinion. In addition to that women, cinematographers can be used as change agents in changing the gender-related stereotypes in the larger society.

As per the outcome of the interviews with the nursing officers, it was clear that the level of knowledge on gender-related issues was not satisfactory among these nursing officers. Compared to other nurses 
in the sample, the nursing officer from the STD unit showed more knowledge on GBV related issues. This is a very interesting finding. Probably as working with STDs requires specialized knowledge and skills, nursing officers attached to the STD units have received specialized training, which has changed their skills and perceptions of GBV.

Most nursing officers revealed that they advise the victims to somehow remain with the husband and be patient with GBV and other related discrimination to safeguard their family lives and their children. Further, they appeared to believe talking about GBV is taboo for a woman and to believe that the woman is to be blamed. Further, they appear to believe that if the husband engages in GBV or related discrimination, the woman should perform a rehabilitative role to change the husband. Failing to do is believed to be a problem with the woman.

It was observed throughout the study that public health staff members had very refined, sophisticated knowledge and skill levels related to GBV compared to staff members who were strictly in hospitals. This is an important finding, which the health ministry needs to explore further. This could be because the public health staff receives targeted training on GBV. Also, it could be that the public health staff receives more training on health care than the hospital staff. Therefore this could be a reflection of the fact that the public health staff and the hospital staff receiving uneven training on GBV and related issues. Therefore, the experience of service users on these matters in a hospital and a public health office such as a MOH would be entirely different.

In addition to this, most health care workers pointed at the lack of knowledge, skills, and sensitization of the health care attendants, janitorial staff, and other workers who are at the bottom of the hierarchy of the health care team. As part of the health care team, they also have access to GBV and related service user information and might respond in detrimental ways due to the lack of relevant knowledge and skills. Therefore it would be of value to provide training to all levels of employees in the health care sector.

Further, there is very little current research on the behavior of the private health care sector and there are no laws and regulations in place to obtain this information. There are reports of all types of violence being concealed by private health care facilities. Therefore, any organization working on GBV and related issues needs to address the issue of transparency and access to information from the private health care sector.

The sample of young adults had some knowledge about GBV related issues. Yet most of the knowledge they possessed was on right-based aspects of GBV rather than the subtle social and attitudinal aspects. Most of their discussions centered on women's rights and GBV was seen exclusively as a women's rights movement. Most women's rights that they identified were related to the type of issues that a young girl under parental authority would face. Namely, the most common example of the violation of women's rights that they identified was not letting girls leave the house at night and not allowing girls to socialize as much as they want with boys. This clearly shows the lack of education and sensitization on GBV during school years. 
The sample from the apparel industry had partial knowledge about GBV related concepts. Most of their discussion points were related to sexual harassment in the workplace. All of them described verbal sexual harassment in the workplace. The entire sample forwarded the idea that women in the apparel industry should be empowered to fight against these. When asked how most of them felt that the women should be taught skills that would help them avoid such situations or would let them delicately get out of such situations. When asked about direct measures such as complaining or legal action, all of them felt that was not a practical path of action, though all of them referred to it as the "correct" path of action. They further described how a spiral of social judgments and attitudes will be thrown out at the woman who takes such a path, which would ultimately create more difficulties for the woman. The participants even opted to describe few examples they have seen.

FGD's with the public health midwives, public health inspectors, and Medical Officer of health

During the FGD's it was apparent that almost all of them demonstrated a sound understanding of GBV and related concepts. They were already using their knowledge in their fieldwork. Most of them had received knowledge on GBV related concepts rather than the skills necessary to use them at a practical level.

According to the outcomes of the FGD's, it was noted that while the traditional gender roles are considered as the norm, additional roles are assumed depending on socio-economic necessities. The consequences of playing such additional or different roles that do not fall within the normative roles had only very few variations in different communities. In all the communities women appeared to shoulder more responsibility for household chores and other roles were adapted on top of these responsibilities. It was very significant to note that while the larger society admired women who played additional or different roles to the existing normative gender roles, at the same time they were belittled. For example, while admiring their contributions to the family economy, most women at the same time criticize things such as the additional trips the woman makes to the workplace, etc. These belittling instances were mostly indirect, mostly hinting at sexual promiscuity. Yet it should be noted that such allegations were not directly made. Most of the belittling was implying such possibilities, rather than direct accusations. According to the participants this tendency was higher in women.

\section{Micro Credit facilities}

All FGD's revealed that the current micro-credit facilities, which target women have resulted in many GBV related issues. These organizations are supposed to target women as their beneficiaries. Mostly these loans/ credit facilities are provided to groups of women, without an accurate assessment of their ability to pay back. Most women are reported to access these facilities without the consent of their husbands or partner. When paying back becomes difficult, these organizations, attempt at seizing property and other household valuables. When the partner finds out, this often leads to marital conflict and violence. In addition to family violence, the participants reported that there is a high chance of the woman being subjected to sexual violence and manipulation by the representatives of the credit company. There have been numerous cases that have been reported where sexual favors were expected in place of overdue repayment installments. In addition to that, as these facilities are given to groups of women, when one woman fails to pay back there are consequences for the whole group. Thus the woman who fails to pay back usually loses her social support system of friends who joined in receiving the credit facility and are sometimes subjected to the violence of their family members. 
The FGD that was conducted in the estate sector pointed out the fact that there were no sufficient services for women who experience violence and discrimination in the area. Especially there was a serious lack of women officers related to such services in the area. In the absence of such services, the participants reported that most women access the police for almost all of their issues. They further reported that the women have a high chance of being abused and creating family conflicts around extramarital affairs in accessing services that are not relevant. Therefore increasing relevant services in these areas is of utmost importance. Further, as they noted there is a lack of service provider personnel who can communicate in the local Tamil language.

While all other FGD's pointed at the increased use of illicit drugs in their areas, the participants from the estate sector did not report such an increase. Instead, they reported increased issues about alcohol abuse. They reported that both men and women alike believed having consumed alcohol was a valid reason for violence. Therefore both men and women tend to forgive and lessen the significance of abuse by males towards women if the man had consumed alcohol. Therefore most men appear to consume alcohol before engaging in conflict-laden encounters with men and women alike.

During the FGD conducted in the Batticoloa area, they pointed out the lack of a professional system of management to address gender-based violence. Most of them also pointed out the lack of adequate training and support to intervene in cases of GBV. They also reported that such incidents are high in the area. In addition to that, they pointed out that intervening against GBV is not included in their duty list. Therefore when they attempt such interventions they face difficulties. They feel such interventions would be more official if it was included in the duty list.

Participants from Point Pedru especially pointed out gender-based violence in workplaces. They felt the health staff should have the skills and legal provisions to intervene on behalf of these cases. They also pointed out GBV related issues that occur in the context of alcohol use and the use of other licit drugs is increasing. Further women are subjected to violence and that female children face difficulties due to the lack of parenting skills in their parents. Therefore the participants were keen to receive training on parenting skills so that they would be able to impart them to their service users.

\section{Conclusions}

Interestingly, GBV appears to be common across different communities and social groups of Sri Lanka. What is even more important is these may service in different forms in different social groups and therefore GBV related interventions should have multiple forms to address issues related to multiple layers of society. Further, while there are issues more specific to different areas and different cultures, most GBV related issues appear to be similar across the different social groups in Sri Lanka. What appears to be different is their mode of expression in society.

In addition to those economic factors appear to have a strong influence in precipitating and perpetuating GBV and related issues. Therefore, economic interventions to counter GBV are of utmost importance. 


\section{References}

Abbbey, A., 2011. Alcohol's role in sexual violence perpetration: Theoretical explanations, existing evidence and future directionsdar_296 481..489. Drug and Alcohol Review, pp. 481 - 489.

Abbey, A., Zawacki, T. \& McAuslan, P., 2000. Alcohol's Effects on Sexual Perception. Journal of Studies on Alcohol and Drugs, pp. 688- 697.

Asian Development Bank, Deutsche Gesellschaft für Internationale Zusammenarbeit (GIZ) GmbH, 2015. COUNTRY GENDER ASSESSMENT SRI LANKA AN UPDATE, Manila: Asian Development Bank, Deutsche Gesellschaft für Internationale Zusammenarbeit (GIZ) GmbH.

Australian Department of Health and Ageing, 2012. About family relationships, s.l.: Australian Department of Health and Ageing.

Choo, E. K. et al., 2014. The Intersecting Roles of Violence, Gender, and Substance Use in the Emergency Department: A Research Agenda. Academy of Emergency Medicine, pp. 1447- 1452.

Dieten, M. V., Jones, N. J. \& Rondon, M., 2014. Working With Women Who Perpetrate Violence: A Practice Guide, s.l.: US Department of Justice.

Dissabandara, L., Dias, S. R., Dodd, P. \& Stadlin, A., 2009. Patterns of substance use in male incarcerated drug users in Sri Lanka. Alcohol and Drug Review, pp. 600 - 607.

Eriksson, T., Smith, N. \& Smith, V., 2017. Gender Stereotyping and Self-Stereotyping Attitudes: A Large Field Study of Managers. Discussion Paper Series, pp. 1- 45.

Glass, N., 2015. Confronting Gender Based Violence. s.1.:Johns Hopkins Centre for Global Health.

Healthy Relationships and Marriage Education Training Program, 2013. Showing Affection and Respect to Strengthen Relationships, Georgia: U.S. Department of Health and Human Services, Administration for Children and Families.

Heise, L, E., M, G. \& M, 2002. A global overview of gender-based violence. International Journal of Gynecology and Obstetrics, pp. 5-14.

Hess, J., 2008. Marital Satisfaction and Parental Stress. Logan: All Graduate Theses and Dissertations , Utah State University.

Hines, D. A. \& Douglas, E. M., 2009. tment \& Trauma Women's Use of Intimate Partner Violence against Men: Prevalence, Implications, and Consequences. Journal of Aggression, Maltreatment \& Trauma, pp. 572 - 586.

Kaighobadi, F. \& Shackelford, T., 2009. INTIMATE PARTNER VIOLENCE, EVOLUTIONARY PSYCHOLOGY. In: Criminological Theory: A Life-Course Approach. Boston: Jones and Bartlett, pp. 1- 26.

Kauffman, C. \& Silberman, J., 2009. Finding and Fostering the Positive in Relationships: Positive Interventions in Couples Therapy. Journal Of Clinical Psychology, pp. 520 - 531.

Kaufman, M., 1999. Men, Feminism, and Men's Contradictory Experiences of Power. In: Men and Power. s.l.:Fernwood Books, pp. 59-83.

Lin, Y. \& Billingham, R. .., 2014. Relationship between Parenting Styles and Gender Role Identity in College Students. Psychological Reports, pp. 250 - 271.

Marinova, J., 2003. Gender Stereotypes and the Socialization Process, Brasilia: United Nations ,Division for the Advancement of Women.

McDowell, L., 1986. BEYOND PATRIARCHY: A CLASS-BASED EXPLANATION OF WOMEN'S SUBORDINATION. Antipode, pp. 311-321.

Mervis, Z., Eve, N., Florence, M. \& Caroline, M., 2013. The relationship between democracy and women participation in politics. Journal of Public Administration and Governance, pp. 168 - 176. 
Miller, J., 2002. Violence and Coercion in Sri Lanka's Commercial Sex Industry. Violence against women, pp. 1044-1073.

Mohd, S., 2016. Gender Based Violence: A Paradoxical Analysis. Journal Of Humanities And Social Science, pp. 118-125.

National Clearinghouse on Family Violence , Canada, 2003. Health Effects on Family Violence, Ontario: Her Majesty the Queen in Right of Canada, represented by the Minister of Public Works and Government Services Canada.

National Dangerous Drug Control Board, Research Unit, 2017. Research Paper Collection IV, Colombo: National Dangerous Drug Control Board, Research Unit.

National Dangerous Drug Control Board, 2017. Handbook of Drug Abuse Information 2017, Colombo: National Dangerous Drug Control Board.

Norris, J., 2008. The Relationship Between Alcohol Consumption and Sexual Victimization. VAW Net Applied Research Forum, pp. 1-13.

Olympic Training and Consulting Ltd, 2016. Adult Training Methodology and Techniques. s.l.:Time Project Partnership.

Perlson, S. \& Greene, M., 2014. Addressing the Intergenerational Transmission of Gender-Based Violence: Focus on Educational Settings, Atlanta: CARE Education.

Plotnik, R. \& Kouyoumdjian, H., 2011. Introduction to Psychology. Belmont: Wadsworth.

Quffa, W. A., 2016. A REVIEW OF THE HISTORY OF GENDER EQUALITY IN THE UNITED STATES OF AMERICA. Social Sciences and Education Research Review, pp. 143-149.

Rawat, P., 2014. Patriarchal Beliefs, Women's Empowerment, and General Well-being. VIKALPA, pp. 43-56.

Reading Youth Violence Prevention Project, 2011. Reading Impact Plan. Pennsylvania: Reading Youth Violence Prevention Project.

Rode, D., Rode, M. \& Januszek, M., 2015. Psychosocial characteristics of men and women as perpetrators of domestic violence. Polish Psychological Bulletin, pp. 53 - 64.

Shastri, A., 2014. Gender Inequality and Women Discrimination. Journal Of Humanities And Social Science, pp. 27- 30.

Somatunga, L. C. et al., 2014. National alcohol use prevalence survey in Sri Lanka. Journal of the Postgraduate Institute of Medicine, pp. 1 -12.

The Australian Domestic \& Family Violence Clearinghouse ,The University of New South Wales, 2011. The Impact of Domestic Violence on Children: A Literature Review, Sydney: Benevolent Society.

UN Women, 2014. A GENDER PERSPECTIVE ON THE IMPACT OF DRUG USE, THE DRUG TRADE, AND DRUG CONTROL REGIMES, s.l.: UN Women.

United Nationas Office on Drugs and Crime (UNODC), 2018. World Drug Report - 2018, Geneva: United Nationas Office on Drugs and Crime (UNODC).

United Nations Development Programme ( UNDP), 2018. Human Development Reports. [Online] Available at: http://hdr.undp.org/en/composite/GII

United Nations office on Drugs and Crime ( UNODC), 2005. South Asia Regional Profile, Geneva: United Nations office on Drugs and Crime ( UNODC).

Women, U., 2018. Advocay Toolkit for Women in Politics. [Online] Available at: http://www.ipsnews.net/publications/keygenderconcepts.pdf 
World Economic Forum, 2017. The Global Gender Gap Report - 2017, Geneva: World Economic Forum.

World Health Organization ( WHO), 2013. Global and regional estimates of violence against women: prevalence and health effects of intimate partner violence and nonpartner sexual violence.. Geneva: World Health Organization ( WHO).

World Health Organization (WHO) - Sri Lanka, 2006. Young People , Colombo: World Health Organization (WHO) - Sri Lanka.

World Health Organization Sri Lanka, 2018. Country Profile on Gender -Based Violence In Sri Lanka., Colombo: World Health Organization Sri Lanka.

Xia, Y., Li, S. D. \& Liu, T., 2018. The Interrelationship between Family Violence, Adolescent Violence, and Adolescent Violent Victimization: An Application and Extension of the Cultural Spillover Theory in China. International Journal of Environmental Research and Public Health, pp. 2 - 15.

Zarar, R., Bukhsh, M. \& Khaskheli, W., 2017. Causes and Consequences of Gender Discrimination against Women in Quetta City. Arts and Social Sciences Journal, pp. 1-6. 